\title{
帯熱延ラインにおけるオンライン再加熱装置の開発
}

大橋秀之*, 福井健展*, 谷田沢 純*

\section{The Development of the Reheating Equipment in the Hot Strip Line}

\author{
Hideyuki Ohashi, Takenobu Fukui and Jun Yatazawa
}

\section{Synopsis}

In Shibukawa Plant, Daido Steel, many grades of the hot strip are rolled, like tool steels, stainless steels, the materials for electronic industry, and so on.

In recent years, demands of the higher grade strip material like superalloys, permalloys and welding materials are increasing. In these materials which are difficult to roll, the edges of rolled materials are prone to crack. This cracking is caused by the tempera. ture drop between the roughing stand and the finishing train.

Shibukawa Plant developed the reheating equipment in the hot strip line. The characteristic of this equipment is that the Ceramic Surface Burner (C.F. B) with high heat transfer efficiency is employed. By using this equipment, the temperature at the edges of materials goes up approximately $60^{\circ} \mathrm{C}$ compared with conventional rolling.

As a result, the occurance of the edge cracking decreased and the relationship between the edge cracking and the edge temperture of the material was made clear.

This paper presents the reheating equipment and the reheating effects.

\section{1. 错}

大同特殊銅排川工場（以下当工場とい5）帯 熱延ラインでは，工具鋼・ステンレス銅・電子機 器材料などを中心に生産している。近年，市場で 使用される素材の高級鋼化・高機能化などにとむ ない, 超合金・バーマロイ・溶接用带など（以下 難加工帯といら）の需要が増加してきた。難加工 帯は圧延温度低下により，製造工程面・品質面で 繁害を引き起こす耳割れなどの問題が発生しやす
1991年 8 月 28 日受付

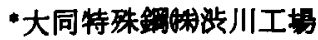

い(耳割れとはFig.1に示す，带鋼エッジ部の割 れである)。耳割れが発生した場合，冷延前にスリ

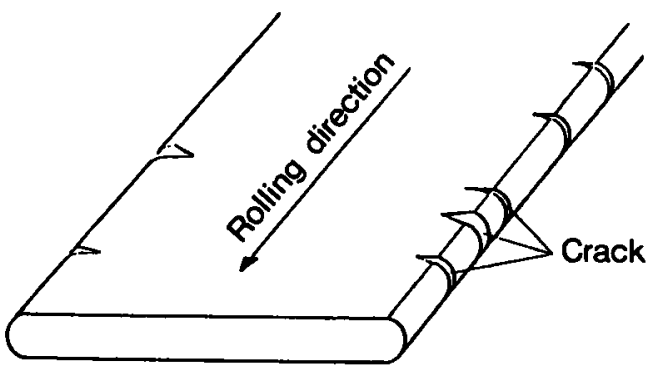

Fig. 1. Location at edge of crack. 
ット工程が追加となり，歩留りロス・工数增加な どの慗害につながる。Fig. 2 に示すよらに耳割れ 発生の要因はいくつか考えられるが，中です材料 温度低下による加工性の悪化が最大の要因と考え られる。そこで材料ェッジ部の温度低下を防止す るために、奻率的に再加熱できるコンパクトな変 置を開発し，仕上列前に設置することにより温度 上昇効果を確認したので，ここに報告する。

\section{2. 带䧼延ライン設借概要}

当工場帯熱延ラインの設備概要を Table 1 K, また設備レイフウトを Fig.3 に示す。帯熱延ライ ンは，粗列に二重逆転水平及び㹂形圧延機をるち， 仕上列には 5 基の四重水平及び㹂形压延機を備 え，各種高級帯を製造している。

\section{3. オンライン再加熱技術}

\section{1 说来の覀題点}

従来の設備では, 粗列から仕上列への搬送過程
でFig. 4 に示すような材料の温度降下があった。 特に，材料後端エッジ部の温度は先端エッジ部に

Table 1. Main specification in Shibukawa Plant.

\begin{tabular}{l|l}
\hline \multicolumn{1}{c|}{ Item } & \multicolumn{1}{c}{ Specification } \\
\hline Reheating furnace & $\begin{array}{l}\text { Pusher type } \times 1 \\
\text { Walking hearth type } \times 1\end{array}$ \\
\hline Roughing train & $\begin{array}{l}2 \text { hi reverse } \\
\phi 680 \times 1100 L \times 1 \\
\text { Edger } \\
\phi 560 \times 330 L \times 1\end{array}$ \\
\hline Reheating equipment & C.F.B.-5stand $\times 4$ burner \\
\hline Finishing train & $\begin{array}{l}4 \text { hi } \\
\text { WR } \phi 320 \times 550 L \times 5 \\
\text { Edger } \\
\phi 650 \times 290 L \times 1\end{array}$ \\
\hline Coiler & $\begin{array}{l}\text { Up coiler } \\
\text { Wrapper roll } \times 4\end{array}$ \\
\hline
\end{tabular}

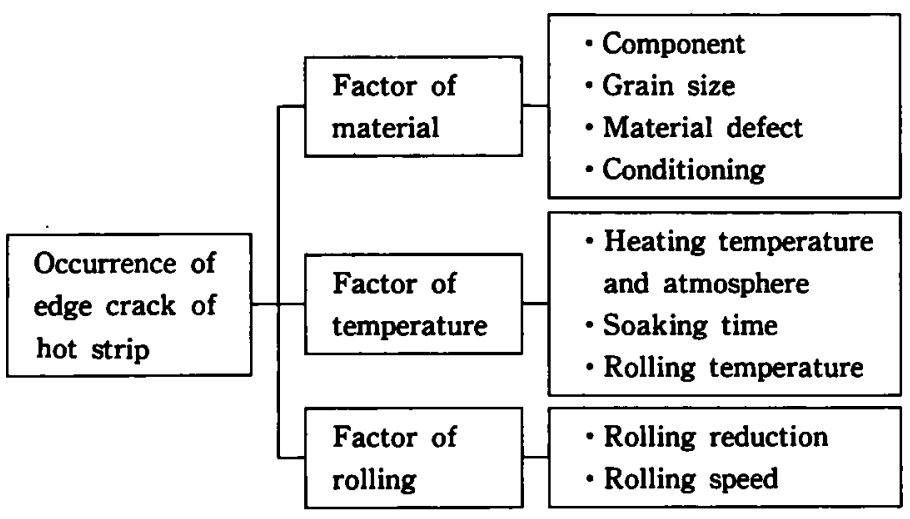

Fig. 2. The factor of occurrence of crack at edge of hot strip.

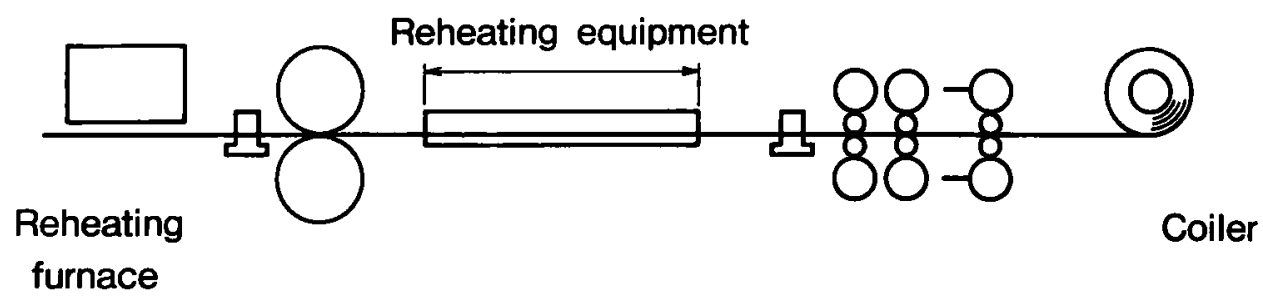

Roughing train

Finishing train

Fig. 3. Layout. 
比べ約 80 ○低下しており，難加工带の耳割れ発生 の最大の要因となっていた。

\section{2 オンライン再加稳法}

上記問題点を解決し， 難加工帯の耳割れを防止

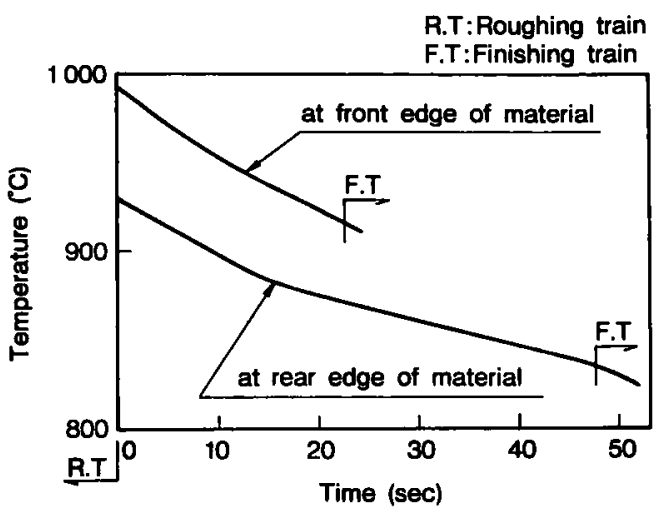

Fig. 4. Changing of temperature at edge of material.
するために，粗列から仕上列間の搬送テーブルを 利用し，オンラインで材料を再加熱する装圈を開 発した。この装固は， 5 基の再加熱燃焼装置とそ の装置の間に設けた保熱ソーンより粠成される。 この設備概要を Fig. 5 に, 設備配置を Fig. 6 に示 す。

本設備の特徽は以下に示すとおりである。

（1）然矢室内を通過中の材料エッシ部を常時急 速加熱するため，Fig.7に示すよらな平面スリッ ト状の高速バーナー (C.F.B : Ceramic surFace Burner) 》を採用し，材料進行方向に取り付けた。

(2) 各種製品幅への対応及び材料の蛇行に対応 するために, Fig. 8 に示すよ5に,ハーナーを水平 より $10^{\circ}$ 傾斜させ取り付けた。

（3）熱効率を高めるため，Fig.6に示すよ5に 然焼室を分散して配置した。また燃焼室間の保熱 ソーンは断熱構造とし，各所に排気筒を設けてド ラフトにて排ガスを保熱ソーン内に強制的に引き

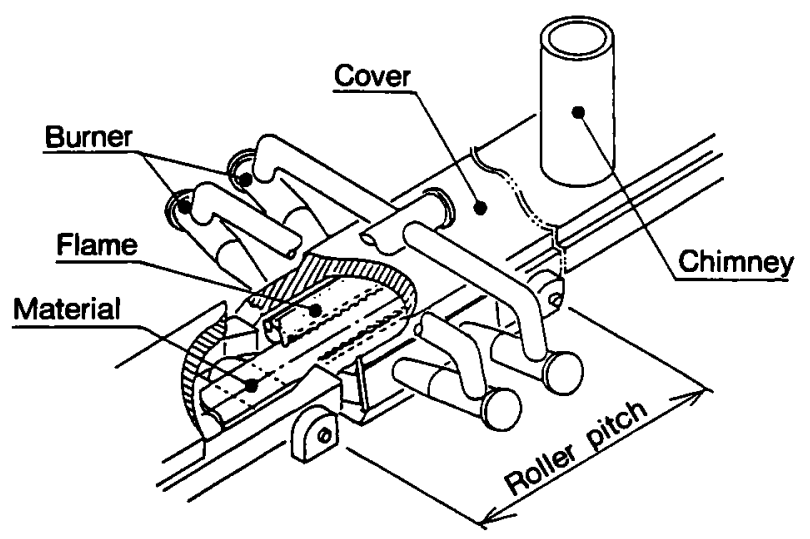

Fig. 5. Burner system.

$(\mathrm{mm})$

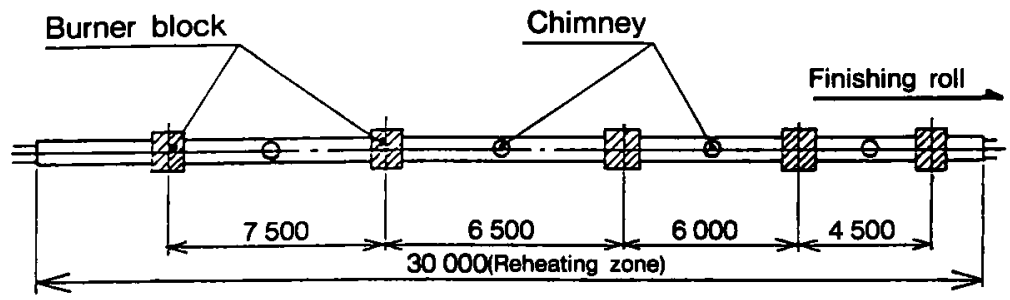

Fig. 6. General view of reheatng equipment. 


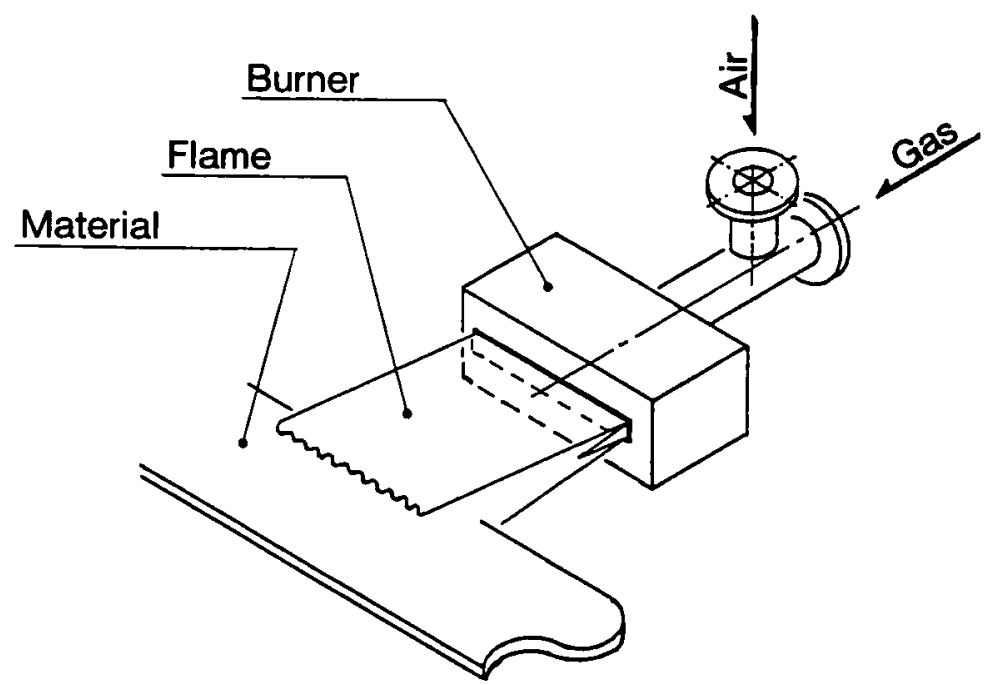

Fig. 7. Location of Ceramic surFace Burner.

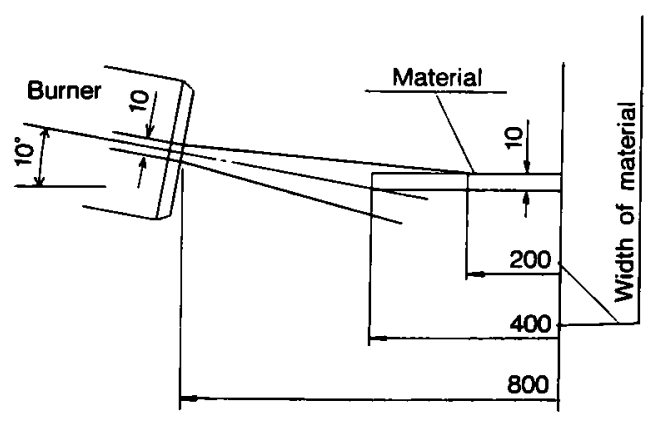

Fig. 8. Burner angle.

込み，排ガスの顕熱を有効に活用している。

(4) 設備がンンハククドあり従来の搬送テーブ ル内に納まるため，着眖・増設が容易である。

\section{3 年温制御}

再加熱襞置を有効に活用するために，以下の方 法を用いて材料ェッシシ部 $(\square 10 \mathrm{~mm})$ の温度推移を 計算し目標温度に到達するよ5然焼室温度・燃烧 方式を制御する。

(1) 輻射云熱による温度変化 $\left(\Delta T_{1}\right)$

$$
\begin{aligned}
\Delta T_{1}= & \frac{2(B+H) \cdot 4.88}{1 / \varepsilon_{1}+\frac{2(B+H)}{F} \cdot\left(1 / \varepsilon_{2}-1\right)}\left\{\left(\frac{273+T_{\mathrm{r}}}{100}\right)^{4}\right. \\
& \left.-\left(\frac{273+T}{100}\right)^{4}\right\} \times S \mathrm{r} \times \frac{L}{C \mathrm{p} \cdot W \cdot H / B}
\end{aligned}
$$

(2) 対流熱伝達にによる温度変化 $\left(\Delta T_{2}\right)$ $\Delta T_{2}=h \cdot 2(B+H) \times(T \mathrm{r}-T) \times S \mathrm{r}$

$$
\times \frac{L}{C \mathrm{p} \cdot W \cdot H / B}
$$

（3）街突伝熱による温度変化 $\left(\Delta T_{3}\right)$

$$
\begin{aligned}
\Delta T_{3}= & \alpha(0.01+0.01 \times 2) \times(T \mathrm{c}-T) \times S \mathrm{c} \\
& \times \frac{L}{C \mathrm{p} \cdot W \cdot H / B}
\end{aligned}
$$

(4) 放冷に上る温度変化 $\left(\Delta T_{4}\right)$

$$
\begin{aligned}
\Delta T_{4}= & -\varepsilon_{1} \times 4.88 \times 2(B+H) \times\left(\frac{T}{100}\right)^{4} \times S_{\mathrm{t}} \\
& \times \frac{L}{C \mathrm{p} \cdot W \cdot H / B}
\end{aligned}
$$

諸俰数は Table 2 に示す。以上の計算式より温 度変化分を $\left(\Delta T_{1}+\Delta T_{2}+\Delta T_{3}+\Delta T_{4}\right)$ とし，絽り 返し計算により温度推移を算出した。なお，温度 計算においては然焼室内はフレームの街突による 強加熱の奻果をみており，その前後は排ガスの奻 果を考虑している。Fig.9にこの計算結果の一例 を示す。この結果より，然焼室内の㞣囲気温度を 制御することで，材料エッシ部を目標の温度に到 達させることが可能である。

\section{4 稼的実模}

再加熱装置使用による材料エッジ温度の実綪を Fig. 10 に示す。仕上列前での材料エッジ部の温度 が上界し，均熱性がよくなっている。また Table 3 のよ5に, 燃焼方法を連続及び間欠然焼に変えて、 
Table 2. Coefficient used in calculation.

\begin{tabular}{l|l}
\hline$B, H, L, W$ & Width, thickness, length and weight of material \\
\hline$F$ & Internal surface area of furnace wall \\
\hline$T, T_{\mathrm{r}}, T_{\mathrm{c}}$ & Temperature of material, furnace and burner flame \\
\hline$S_{\mathrm{r}}, S_{\mathrm{c}}, S_{\mathrm{r}}$, & $\begin{array}{l}\text { Time of heat transfer. ( } \mathrm{r}: \text { Radiant and flow } \\
\mathrm{c}: \text { Impact. } \mathrm{f}: \text { Air cool) }\end{array}$ \\
\hline$e_{1}, \varepsilon_{2}$ & Emissivity of material and furnace wall \\
\hline$h, \alpha$ & $\begin{array}{l}\text { Surface coefficient of heat transfer in radiant and } \\
\text { flow( }(h) \text { and in impact, radiant and flow }(\alpha)\end{array}$ \\
\hline$C_{\mathrm{p}}$ & Specific heat of material \\
\hline
\end{tabular}

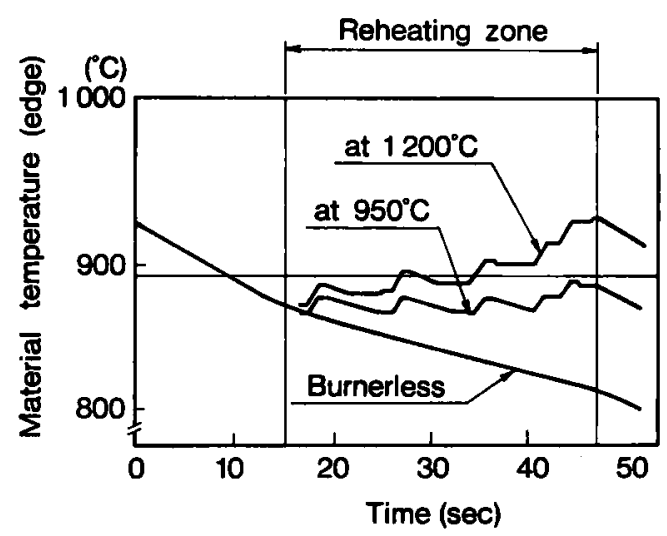

Fig. 9. Thermal simulation.

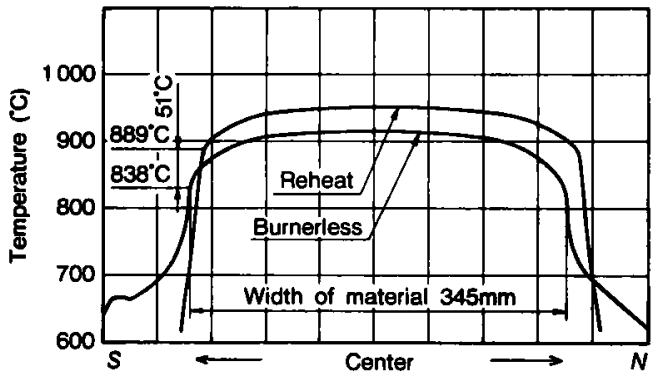

Fig. 10. Actual temperature of material.

Table 3. Operation of reheating equipment.

\begin{tabular}{l|l|l|l}
\hline \multicolumn{2}{|c|}{} & \multicolumn{1}{|c|}{ Intermittent reheating } & Continuous reheating \\
\hline \multirow{3}{*}{$\begin{array}{l}\text { Combustion } \\
\text { control }\end{array}$} & $\begin{array}{l}\text { Off } \\
\text { material }\end{array}$ & Off combustion & Thermal control \\
\cline { 2 - 4 } & $\begin{array}{l}\text { On } \\
\text { material }\end{array}$ & Full combustion & Full combustion \\
\hline $\begin{array}{l}\text { The way of } \\
\text { heat transfer }\end{array}$ & $\begin{array}{l}\text { - Impact heat transfer } \\
\text { - Flow heat transfer }\end{array}$ & $\begin{array}{l}\text { - Impact heat transfer } \\
\text { - Radiant heat transfer } \\
\text { - Flow heat transfer }\end{array}$ \\
\hline Object of reheating & Tool steels & $\begin{array}{l}\text { Welding stainless steels } \\
\text { Super alloys, Permalloys }\end{array}$ \\
\hline
\end{tabular}




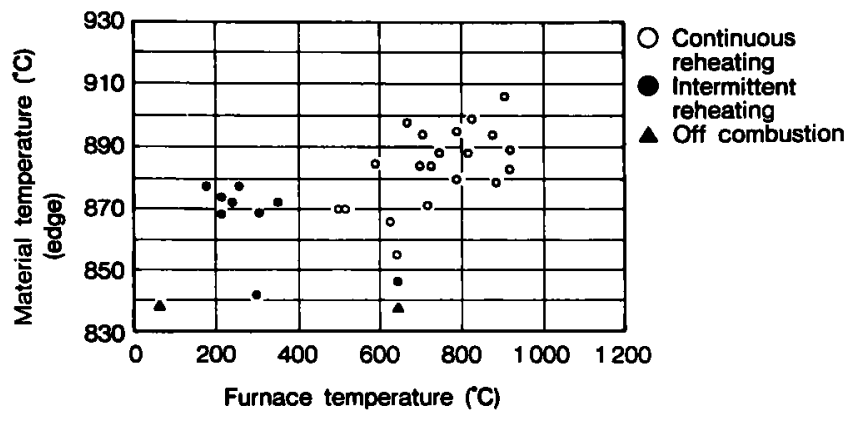

Fig. 11. Thermal changing in two operation.

材料エッジ部の温度の变化を調查した。その結果 を Fig. 11 に示す。再加熱装置の妒内温度上昇に より，材料エッジ部温度を上昇させることができ， 各種制御により好率的に材料エッシ部を再加热す ることができる。

\section{4. 桔}

当工場では，特に難加工帯（超合金・ハードハ 一ムなど）の耳割れ改善を目的に, 仕上列前の再

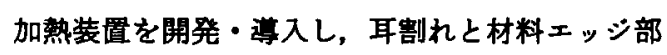
温度との成係について調查・検討した結果, 以下 の成果を得た。

(1) Fig.12 に示すよらに, 材料エッジ部温度が 上昇するのに伴い耳割れ橆生率は明らかに低下し ている。

（2）再加熱装置の炉内温度を制御することによ って，材料エッジ部温度を制御することができる ことがかかった。

今後はさらに再加熱温度の上昇を目指していく とともに, 耳割れ一材料温度一成分の関係を明ら

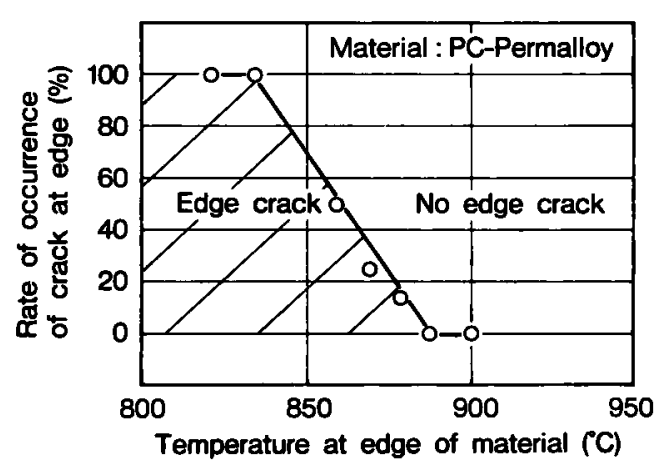

Fig. 12. Relation of temperature and crack at edge of material.

かにし，難加工帯の品質向上にむけて，操業・技 術開発など努力していく所存である。
(文
嗝)

1）池田，森田，落合：工羓加熱，24(1987)，4, 32 